\title{
Fundamentación teórica y propuesta metodológica para el abordaje de la alfabetización visual en el nivel preescolar
}

Andrea Soto Grant

Asesora curricular, Programa de Apoyo Curricular y Evaluación de los Aprendizajes, UNED, Costa Rica; asotogrant@gmail.com

Recibido: 30 de agosto del 2016

Corregido: 13 de octubre del 2016

Aceptado: 16 de noviembre del 2016

\section{Resumen}

El ensayo se deriva de la investigación realizada para la obtención del grado de Maestría en Planificación Curricular de la Universidad de Costa Rica. Uno de los resultados de la investigación fue la elaboración de una propuesta metodológica específica de alfabetización visual para el nivel de preescolar, tomando en cuenta las particulares que este grupo etario conlleva. Con este fin se realizó una revisión teórica sobre las diversas metodologías para el aprendizaje de la alfabetización visual, así como información teórica específica en torno al aprendizaje de los niños y niñas en edad preescolar. La propuesta metodológica consta de las fases para el desarrollo de las estrategias didácticas que se desarrollarán en el aula, así como los pasos para su formulación e implementación. Se toma en cuenta la teoría constructivista social de Vigotsky, así como los procesos de aprendizaje propuestos por Bruner y las fases de la enseñanza formuladas por Hernández.

Palabras clave: Alfabetización Visual, Educación Preescolar, Metodología, Innovación Pedagógica, Estrategias educativas.

\section{Abstract \\ Theoretical foundation and proposed methodology for addressing literacy visual preschool education}

This essay is derived from a research conducted for obtaining master's degree in Curriculum Planning from the University of Costa Rica. One of the products of this research was the development of a specific methodological proposal for visual literacy preschool level taking into account the particular age group that this entails. For this purpose a theoretical review of the various methodologies for learning visual literacy and specific theoretical information about learning of children in preschool is performed. The proposed methodology consists of the steps for the development of teaching strategies to be developed in the classroom, as well as steps for formulation and implementation. It takes into account Vygotsky's social constructivist theory and learning processes proposed by Bruner and phases of teaching made by Hernandez.

Key words: Visual learning, Preschool education, Methodology, Teaching method innovations, Educational strategies. 


\section{INTRODUCCIÓN}

En los últimos años, la humanidad ha tenido un vertiginoso aumento en el uso de las tecnologías como medio de comunicación (TIC) individual o masiva.

Durante el siglo pasado se utilizó, mayormente, la comunicación escrita a través de diferentes medios (cartas, correos electrónicos, mensajes de texto MSM, entre otros) con el fin de enviar y recibir información. La intensidad en la utilización de esta forma de comunicación ha disminuido durante el presente siglo, para dar paso a la maximización del manejo de la información en forma totalmente visual (emoticones, imágenes publicitarias, caricaturas, íconos de establecimientos, conversaciones mediante video), es decir, sin el empleo del alfabeto escrito.

Debido a la utilización masiva de la forma de comunicación visual incrementada por la utilización de las TIC, se hace necesario comprender no solo lo que las imágenes representan visualmente, sino también captar el significado intrínseco y poder interpretarlas en alguna medida. En el presente siglo, la comunicación visual ha demostrado un gran predominio en lograr enviar mensajes de forma masiva y en captar el interés por medio de las TIC, maximizando los resultados esperados en cuanto a la influencia de la información; en otras palabras, la sociedad actual, en general, está dando un giro de lo lingüístico hacia lo icónico como producto de la visualidad masiva de la información (Rodríguez, 2008).

Bajo este contexto comunicativo, en el que las imágenes portan una gran cantidad de información explícita e implícita, es que se están desarrollando la mayoría de los niños y niñas, es decir, que se encuentran rodeados de una gran cantidad de información visual (en revistas, vallas publicitarias, televisión, redes sociales, aplicaciones de celular, anuncios impresos) para lo cual no requieren necesariamente de saber alfabetos textuales para poder entender, en cierta medida, el mensaje transmitido. La interpretación del mensaje que pueden hacer los niños y niñas, la realizan desde su propia experiencia, otorgándole significado desde lo que hasta ese momento han vivido y, en muchos casos, los mensajes visuales van más allá de su experiencia infantil (en el caso de mensajes visuales dirigidos a otras edades).

Por estas razones se dice que los niños y niñas han iniciado su camino hacia la alfabetización visual de manera empírica y espontánea, entendiendo que la alfabetización visual implica la existencia de un lenguaje visual en el cual los signos culturalmente fabricados poseen un propósito específico de comunicar, por tanto este tipo de alfabetización debería ser una propuesta pedagógica formal (Ferreras y Vergilio, 2008).

Los signos culturalmente fabricados y transmitidos de manera visual por los medios son de gran relevancia para la formación intelectual y personal de los niños y niñas ya que van a insertar patrones y valores que permearán sus futuras decisiones (Ferrer y Guanipa, 2007).

Al visualizar el contexto se ha planteado la necesidad de realizar el cuestionamiento de si las imágenes han sido interpretadas correctamente por el receptor o si el mensaje ha sido captado en su totalidad, así como el valorar si las personas (infantes o adultos) tienen el nivel de interpretación para poder distinguir y separar la información con el fin de escoger mejor un producto o servicio entre muchas opciones, o de elegir en qué creer o en qué no con respecto a los valores intrínsecos en la imagen.

\section{JUSTIFICACIÓN}

Debido a la relevancia que está adquiriendo para la sociedad el tema de la interpretación, codificación y decodificación de mensajes culturales en la imagen, Ibarra y De la Llata (2010) plantean el reto social y educativo de lograr el desarrollo de las habilidades que se requieren para organizar la información 
adquirida por diversos medios (digitales o convencionales) con el fin de poder llegar a discriminar la información y valorar la utilidad de estos mensajes para resolver problemas de la vida diaria.

Sin embargo, el aprendizaje de la lectura de imágenes continúa en un papel secundario en el ámbito de la educación formal, lo que puede dar como resultado personas con poca formación específica para interpretar y discriminar los mensajes visuales que les rodean. Según Ferradini y Tedesco (1997) esta formación con la imagen debe ser un trabajo pedagógico y formar parte del proceso educativo desde una visión formal.

Regalado (2008) también plantea esta necesidad, de que la educación formal se involucre en la alfabetización visual, desarrollando proyectos curriculares formales que incluyan este tipo de alfabetización. La autora enfatiza que este tipo de aprendizaje visual posibilitará en el estudiante el dominio del lenguaje icónico y como consecuencia será una persona crítica de su entorno y de los mensajes que recibe.

Atendiendo a estas necesidades es que surge la formulación de esta propuesta metodológica para ayudar a formalizar el proceso de alfabetización visual en el ámbito escolar. El proceso formal puede darse desde el nivel educativo básico (en Costa Rica es la educación preescolar), el cual abarca todas las edades previas al ingreso a la educación general básica o la educación primaria. El nivel educativo de preescolar es un peldaño importante para la continuación de este tipo de alfabetización en los niveles siguientes.

Un ejemplo de la capacidad que poseen los niños y niñas para la decodificación de las imágenes y que enfatiza la importancia de iniciar el proceso en este rango de edad lo brindan Perner y Karmiloff (citados por León, 2006), los investigadores presentan su Teoría de la Mente, la cual inicia señalando que el periodo entre los 2 y 4 años es crucial para desarrollar el sistema relacional entre las imágenes y sus significados o representaciones, ya que están en la posibilidad de interpretar las imágenes visuales (gestos, marcas distintivas, colores) y asignarles un significado con respecto a su sistema de crianza.

Mediante la Teoría de la Mente se indica que a partir de los 4 años de edad los niños ya son capaces de explicar sus propias interpretaciones del mundo, y llegan a entender los diferentes significados que le otorgan a una misma imagen varias personas. Así también los niños en este rango de edad logran diferenciar las representaciones iconográficas de las imágenes reales y logran relacionarlas entre sí; hasta llegar a trasladar esas imágenes y significados a otros contextos de su vida cotidiana.

Los rangos de edad presentados en estos dos extractos de la Teoría de la Mente son los que se integran en los ciclos del nivel de preescolar costarricense, por lo que partiendo de este interés por involucrar la alfabetización visual en la educación formal desde edades tempranas surge el interés por investigar sobre los temas relacionados con la temática y así poder establecer una metodología adecuada a las características de las edades preescolares, con el fin de estimular las habilidades necesarias específicas para la alfabetización visual.

\section{DESARROLLO DEL TEMA}

\section{Alfabetización visual}

Para poder establecer una metodología apropiada para la alfabetización visual, que se pueda adaptar a las necesidades educativas del contexto costarricense y adecuada a las características del rango de edad preescolar, primero se debe explorar el significado y las implicaciones del término así como su importancia y pertinencia en la educación formal de los niños y niñas. 
La alfabetización tradicionalmente había sido entendida como la lectura y comprensión de textos escritos bajo la utilización de palabras, sin embargo Teubal (2010) señala que este concepto ha ido evolucionando hasta incluir otros tipos de lenguaje. Ante la ampliación del término, se plantea la necesidad de que los lectores de todo tipo de textos estén alfabetizados para poder entender y elegir qué tipo de información les es más útil, de la misma manera que se realiza en la lectura de textos escritos.

Como respuesta surge la alfabetización visual definida por Villa (2008) como "un proceso por medio del cual una persona potencia la habilidad para comprender imágenes, usarlas para diferentes propósitos y emplearlas como vehículos del pensamiento y del aprendizaje" (p. 202); de esta manera, quien pasa por este proceso adquirirá la capacidad de identificar todos los componentes que integran las imágenes, además de entender lo que ellas representan.

La alfabetización visual, vista solo como la lectura externa de imágenes puede dar la falsa sensación de ser una lectura que facilita el acceso a la información, sin embargo, el correcto uso del lenguaje visual y por ende la correcta lectura del mensaje intrínseco necesitará de capacitación específica en cuanto al entorno cultural que rodea la imágenes, con el fin de desarrollar habilidades, conocimientos y valores que lleven al estudiante a diferentes niveles de interpretación, esto por ser un proceso tan complejo como la lectura de textos escritos (Ferrer y Guainipa, 2007).

La imagen como medio visual es un tipo de lenguaje, pero no es universal en su totalidad ya que lo integran gran cantidad de características específicas que exigen la comprensión de convenciones existentes y solo se puede educar desde un proceso sistemático que requiere de ciertas habilidades específicas para su interpretación (Llorente, 2000).

Aparicio y García (1998) también señalan que el hecho de ser un lenguaje particular para una sociedad específica va a tomar relevancia la premisa anterior de que debe ser enseñado mediante un proceso formal al igual que el lenguaje textual; es decir, cada sociedad va a tener su propio lenguaje visual mediante el cual va a transmitir mensajes desde sus conceptos, códigos y valores, "se alfabetiza porque hay un lenguaje; porque hay un lenguaje es necesario alfabetizar" (p. 12).

Al contener el mismo nivel de complejidad que cualquier otro tipo de lenguaje, Barragán y Gómez (2012) plantean retos al sistema educativo formal, tales como la necesidad de pensar que los fenómenos visuales que captamos son un hecho socio-cultural y que influye en la vida de las personas de diferentes maneras, así como pensar en la alfabetización visual como un proceso que involucra componentes complejos de pensamiento, propios de la lectura.

Como se planteó en el apartado anterior, surge la necesidad de iniciar el proceso formal a edades tempranas ya que la lectura no es solo la decodificación de los elementos, sino también la comprensión del significado, además del aprendizaje de sus propias normas y estructuras (Aparicio y García, 1998).

Según Calle (2008) los niños y niñas poseen la capacidad cognitiva de comprender los mensajes codificados en las imágenes desde el nivel literal, visual y metafórico; además, el desarrollo de esta capacidad lectora favorecerá la identificación de formas y su asociación directa con el mundo que los rodea. Así, es importante que la alfabetización visual dirigida a preescolares incorpore tanto la identificación de elementos incluidos en la imagen como su contenido.

En la misma línea, Perner (citado por León, 2016) enfatiza que niños y niñas, en edades previas a la escolaridad, pasan de un sistema pre-teórico de la mente a una teoría relacional, por lo que empiezan a comprender la relación con su entorno según la perspectiva con que sea observado y logran brindar una explicación de las variaciones de la realidad y las distintas maneras de actuar con respecto a ellas.

La oportunidad de estimular la alfabetización visual en la edad preescolar puede ser fundamental para el desarrollo de capacidades futuras (la percepción, la interpretación, la reflexión y las respuestas) a 
partir de las experiencias emocionales y simbólicas que se experimentan en los primeros años de vida; de igual manera, para la adquisición de patrones y valores culturales que van a marcar varias facetas de su vida futura.

Ante lo expuesto, cobra gran importancia el proceso formal en alfabetización visual desde edades preescolares, con el fin de orientar la adquisición e interpretación de los códigos culturales transmitidos por las imágenes a las que se encuentran expuestos los niños y niñas en la sociedad de la información, en otras palabras, ir formando e informando a los futuros adultos.

\section{La alfabetización visual y los procesos de aprendizaje}

En esta búsqueda de la formalización de la alfabetización visual se deben establecer los procesos de aprendizaje adecuados al tipo de lenguaje por desarrollar y a las edades meta, en este caso las edades preescolares. Por tanto, se exploran las teorías que se acercan a esta disciplina y se fortalece la fundamentación de su formulación.

Un ejemplo de las teorías que mencionamos anteriormente es la formulada por Bruner (1996) en la cual el desarrollo mental del ser humano parte de una moneda de intercambio cultural que será el lenguaje (desde cualquiera de sus manifestaciones y en cualquier edad) que desencadenará una serie de puntos de vista sobre el mundo circundante que se convierten en representaciones mentales.

Por su parte, las representaciones adquieren un significado que le es otorgado al concepto mediante la negociación (o socialización) con el fin de llegar a un resultado en la mente del ser humano que modificándose modificará según las negociaciones presentes a lo largo de las diferentes etapas de su vida, es decir, "casi todo aquello con que nos relacionamos en el mundo social... no podría existir si no fuese por un sistema simbólico que le da la existencia a ese mundo" (p. 96). Ese sistema simbólico no es solo la adquisición de los conocimientos como tales, sino producto de las experiencias vividas.

Las experiencias se desarrollan mediante métodos de instrucción, en los cual se observa al instructor realizando demostraciones específicas mediante las cuales el niño o la niña pueda aprender lo que se debe o no hacer (a manera de imitación). Otra forma fundamental de instrucción es utilizar un sistema de símbolos donde el instructor brinda hechos y explicaciones sobre un tema por medio de gráficos, modelos, proyecciones (Bruner y Olson, 1973).

Con el fin de complementar las formas de instrucción, el constructivismo social plantea dos tipos de aprendizaje: el aprendizaje cooperativo que es el proceso de aprendizaje mediante la socialización de la información entre los individuos; y el aprendizaje mediado cuando una persona que posee mayor información instruye y guía a un estudiante en el proceso (Hernández, 2007).

Estas formas de instrucción y aprendizaje, mezcladas entre sí y estructuradas de tal manera que se aprovechen todos los beneficios de cada tipo, van a fomentar el aprendizaje de las habilidades requeridas para lograr una alfabetización visual teniendo en cuenta que la transmisión de los significados se realiza de manera cultural y será comprendido según sus propios valores y códigos.

Asimismo, Vygotsky (1979) afirma que el proceso de aprendizaje de los conceptos culturales se va a desarrollar de dos maneras: primero se realiza una interacción social en el que uno o más agentes funcionan como guías en el proceso de aprendizaje del concepto (proceso interpersonal); luego el infante realiza una reconstrucción interna de los estímulos externos (proceso intrapersonal). La doble formación se evidencia cuando el infante logra desarrollar una "conducta para guiarse a sí mismo, y que antes había sido utilizada en relación con otra persona, en el momento en que organiza sus propias actividades de acuerdo con una forma de conducta social consigue aplicar una actitud social a sí mismo" (p. 52). 


\section{Zona de Desarrollo Próximo}

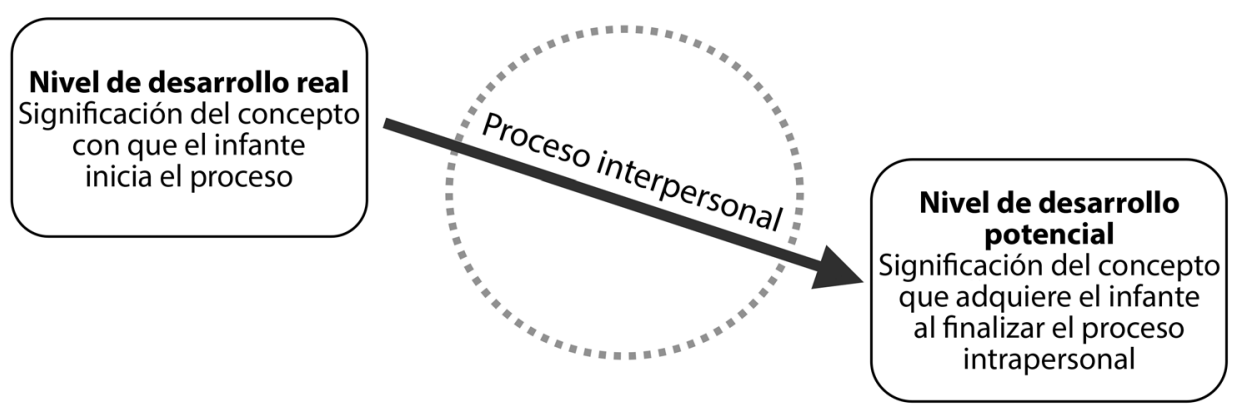

Figura 1. Zona de Desarrollo Próximo. Fuente. Elaboración propia.

De esta manera, el agente que interviene en la zona entre el aprendizaje interpersonal y el intrapersonal debe tomar en cuenta el nivel real de desarrollo del concepto que posee el infante al momento de iniciar un proceso de aprendizaje, el cual se determinará por el conocimiento real del niño o la niña para solucionar un problema por sí mismo; luego se debe estimular ese conocimiento real y llevarlo al nivel de desarrollo potencial (lo que el infante pueda lograr en la resolución de su problema con la ayuda de ese agente más capaz), este proceso se denomina Zona de Desarrollo Próximo, ver figura 1, (Vygotsky, 1979).

Al finalizar la interacción, lo que fue en un principio el nivel de desarrollo potencial para realizar el proceso de aprendizaje se convertirá en el nivel de desarrollo real, será así el punto de partida para visualizar otro proceso en el desarrollo y profundidad de nuevos elementos culturales (Vygotsky, 1979).

Estas teorías provenientes de Bruner, Vigotsky y el constructivismo social sobre los procesos de aprendizaje del ser humano, son complementadas por las fases de la enseñanza propuesta por Hernández (1993) en la búsqueda para formular una metodología que incorpore componentes educativos didácticos.

Hernández (1993) establece tres fases para el desarrollo de los procesos de enseñanza (figura 2). La primera fase es la llamada Previsión, en la cual se realiza la formulación de los objetivos por cumplir en el
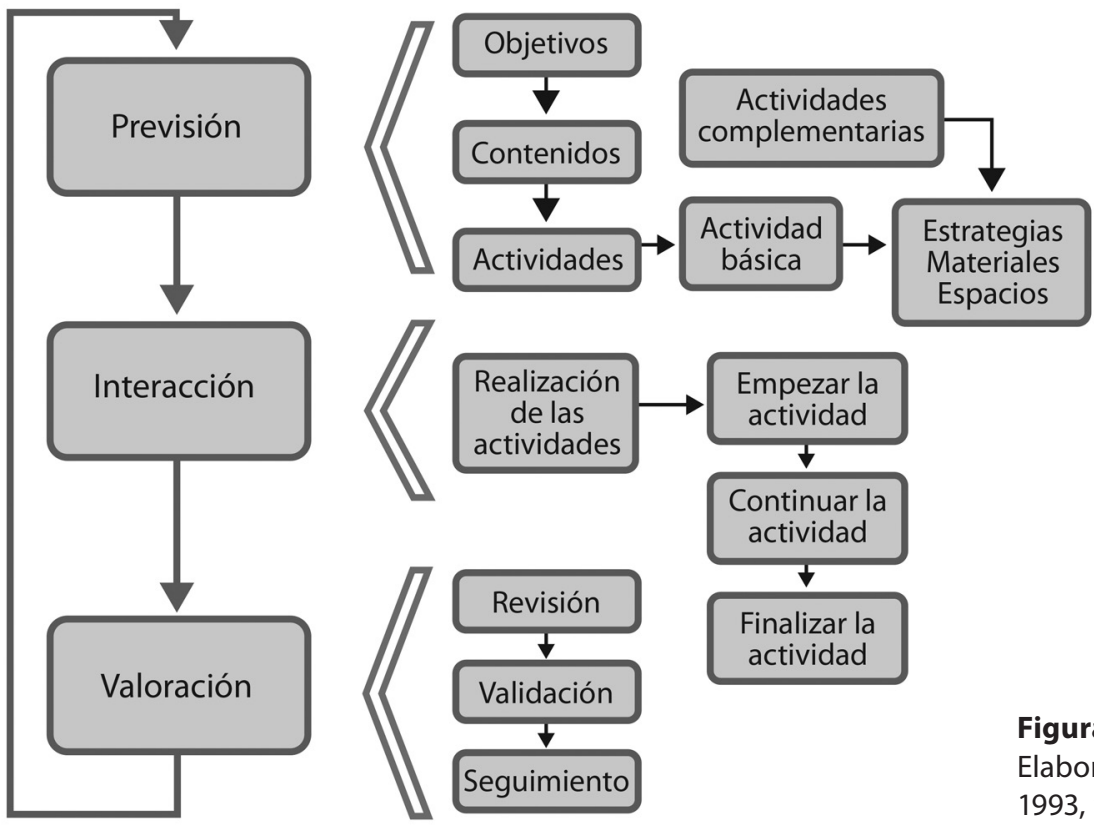
proceso de enseñanza, así como los contenidos por impartir. Una vez formulados estos dos primeros pasos de la fase, se establece la actividad por desarrollar y se planifican actividades complementarias que se requieren para reforzar el contenido; también se establecen las estrategias específicas, los materiales necesarios y la búsqueda de los espacios físicos idóneos para el desenvolvimiento de la o las actividades.

Después de planear esta primera fase, se realiza la Interacción (segunda fase) en la cual se ejecutan los elementos que se planificaron en la fase anterior, para esto se divide la ejecución en tres etapas: se inicia la actividad con una introducción; se continúa con el desarrollo de la actividad y se finaliza la actividad.

En la tercera fase, se realiza una revisión de los avances y hallazgos obtenidos, se validan las acciones que fueron elegidas y se brinda un seguimiento al proceso de enseñanza. Al finalizar el proceso, se realiza de nuevo, pero planteando otros objetivos, contenidos y actividades de enseñanza.

\section{Habilidades y elementos de la alfabetización visual}

Mediante la alfabetización visual, el o la estudiante va a transformar los conceptos culturales transmitidos mediante la utilización de tres sistemas de representación de la imagen:

La representación enactiva está directamente relacionada con las sensaciones y manipulaciones a las que tenga acceso el niño o niña. La representación icónica requiere de imágenes y esquemas complejos para representar el entorno, por lo cual, se deben haber estimulado habilidades necesarias para la interpretación de la imagen. La representación simbólica requiere de símbolos que son abstractos, no necesariamente se asemejan a la realidad, se puede representar objetos que no han sido vistos en la realidad por el estudiante. (Aramburu, 2004, p. 2)

Los tres sistemas de representación mencionados sirven para organizar el tipo de actividades visuales que se implementarán en el proceso de alfabetización visual, con el fin de lograr estimular cada uno de las sistemas de representación relacionados con la lectura de una imagen y su decodificación, en aras de entender su significado.

Los sistemas de representación se van a vincular con los procesos cognitivos que se logren estimular en las edades preescolares para asegurar la recepción y discriminación adecuada del concepto cultural (Crescenzi, 2014).

Durante el proceso cognitivo de estimulación de la alfabetización visual, los niños y niñas pueden llegar a reconocer elementos específicos de las imágenes, así como lo que ellas representan. Según Villa (2008), lo anterior implica que el lector infantil llegue a conocer la morfología específica y la dimensión semántica necesarias para identificar la imagen desde lo denotativo y connotativo de la misma.

Cada una de las habilidades citadas es definida por Ferrer y Gómez (2013), el significado denotativo de la imagen es la decodificación del mensaje desde lo descriptivo, lo que se capta de manera directa identificando todos los elementos que constituyen la imagen y que tendrá sus propios significados en relación con el uso de las formas, los colores, las combinaciones, etcétera. Mientras, en el significado connotativo las experiencias previas intervendrán en la decodificación del mensaje otorgándole un significado a partir de una reflexión.

En palabras de Regalado (2008), el proceso de alfabetización visual conlleva dos acciones interrelacionadas: la acción de ver las características de la imagen, es decir la denotación; y la acción de leer e interpretar el mensaje, es decir la connotación. 
En cuanto al proceso denotativo, Ortega (2011) se refiere a elementos básicos de la imagen como el alfabeto visual. Estos son: el punto, la línea, la forma, la escala, la angulación, la textura, la iluminación, el tono y el color.

La manera en que se conforme una imagen intervendrá en su interpretación (basado en las experiencias culturales previas), de esta manera la denotación y la connotación van a estar estrechamente ligadas en la decodificación del mensaje cultural.

En ambos casos de lectura, denotativa y connotativa, es importante como proceso paralelo la estimulación de la percepción visual. Según Ferrer y Guanipa (2007), la percepción visual es un proceso cognitivo complejo que se estimula mediante estrategias y recursos, los cuales logran que los estudiantes adquieran la capacidad de percibir e interpretar todos los elementos básicos de la imagen. Estos procesos cognitivos llevan implícitos la capacidad de ver la imagen, de conocer la estructura que la conforma y cuáles valoraciones le confiere el individuo a la misma.

En lo referente al proceso cognitivo de percepción visual, el cual va a aportar componentes importantes en la interpretación de imágenes, Bravo (2004) señala que para la lectura de imágenes y la interpretación de las mismas existen varios subprocesos involucrados, los cuales pueden estimularse con el fin de potenciar las habilidades de denotación, estos subprocesos son: recepción visual, asociación visual, discriminación visual, figura fondo visual, cierre visual, memoria visual, constancia perceptual visual, clasificación, seriación e integración.

Con base en la información sobre la necesidad de incorporar el proceso formal de la alfabetización visual desde edades preescolares, así como la teoría sobre la forma de aprendizaje en la cual intervienen los factores culturales presentes en la decodificación de los mensajes visuales y los procesos cognitivos propios del proceso de lectura visual, se realiza el planteamiento de una metodología basada en las características propias de la educación preescolar costarricense y se incorporan elementos específicos de la alfabetización visual para que sean utilizados como proceso paralelo a la planificación de las estrategias didácticas que se plantean para el abordaje de los contenidos y temas propios del programa.

\section{PROPUESTA METODOLÓGICA PARA UNA ALFABETIZACIÓN VISUAL EN EL NIVEL DE PREESCOLAR}

La presente propuesta metodológica forma parte de una investigación realizada cuyo producto fue la elaboración de un módulo didáctico enfocado a la estimulación de habilidades específicas relacionadas con la alfabetización visual. La metodología fue aplicada en la planificación de las actividades del módulo y durante la ejecución del mismo. La validación del módulo se realizó con 30 niños y niñas que cursaban el ciclo de transición en un jardín de niños público, ubicado en una zona con un nivel y un contexto socio-económicos diversos.

El módulo y la propuesta metodológica que lo acompaña se realizan bajo la premisa de adaptabilidad a cualquier rango de edad dentro del nivel preescolar, con el fin de ser consecuentes con lo requerido en el programa de estudios para el nivel de preescolar en el cual se adaptan los contenidos y objetivos a las características y nivel de conocimiento específicos para la población particular de cada docente, partiendo de un diagnóstico de los niveles de conocimiento con el que ingresan al periodo lectivo.

El esquema adapta la forma de planificación presentada en el programa de estudios del Nivel Preescolar del Ministerio de Educación de Costa Rica (MEP). El programa plantea dos fases para la planificación de las actividades: el pre-planeamiento en el cual se identifican los intereses del niño o niña, se hace un diagnóstico y se selecciona la forma de trabajo; y el planeamiento donde se eligen los contenidos relacionados con el tema escogido, se seleccionan las actividades y se evalúan los resultados. 
La propuesta también debe incorporar la secuencia didáctica de la ejecución de las actividades, es decir, el inicio, desarrollo y cierre de la actividad. Esta secuencia se encuentra en coherencia con las fases de la enseñanza de Hernández (1993), lo cual es parte de la fundamentación teórica relevante en la propuesta.

La propuesta metodológica no se puede alejar de los parámetros especificados en el programa de estudios del MEP, debido a que el fin último es su incorporación a la dinámica educativa del aula preescolar. Sin embargo, al ser una propuesta metodológica para incorporarse como complemento a los contenidos y temas propios del programa y específica para la alfabetización visual, se plantean cuatro fases con el fin de dividir las fases propuestas por el MEP. Esta división se basa en la relación de interacción directa entre el agente (docente) y los niños y niñas ya que se consideran como procesos de reflexión independientes.

Las cuatro fases, planteadas en la presente propuesta metodológica, integran la teoría sobre la manera en que se aprende, según Bruner, e incorpora la teoría sobre la Zona de Desarrollo Próximo en cuanto al papel del agente para la estimulación y potenciación de los elementos y habilidades específicas de la alfabetización visual, toma también en cuenta las características específicas y necesidades de los niños y niñas en edad preescolar relativas al proceso de lectura e interpretación de imágenes.

En la propuesta no se abordan contenidos o temas específicos, sino "conceptos". Lo anterior debido a la razón de ser de la alfabetización visual, la decodificación e interpretación de gran cantidad de conceptos culturales implícitos en las imágenes desde la estimulación de las habilidades que lleven a los niños y niñas (futuros adultos) a poder interpretar la información y elegir si es pertinente para integrarla a su vida cotidiana o no.

El módulo realizado contiene estrategias específicas divididas en dos partes, una dirigida hacia las habilidades denotativas, donde se incorporan todos los elementos básicos que conforman la imagen y se toman en cuenta estrategias pertinentes al ciclo de transición; y una segunda parte enfocada hacia las habilidades connotativas, es decir, a la interpretación cultural de la imagen de manera integrada.

Por tanto, la metodología propuesta no puede estar desligada de lo que se debe realizar, a nivel didáctico, con el programa de estudios oficial, pero refuerza las dinámicas del aula con la evidente intención de estimular la alfabetización visual.

\section{Fases de la propuesta metodológica}

En la fase I se debe partir del conocimiento previo que el niño o la niña posee y su nivel de conocimiento específico sobre el concepto que se desarrollará en las siguientes fases, es decir, se aplica una evaluación diagnóstica mediante la observación y la socialización con los pares para establecer el punto de partida de lo que implica el concepto desde la interpretación inicial de lo que significa.

En la fase II, a partir de la información obtenida en la fase anterior, se establecen los objetivos específicos que se requieren para cumplir con los fines propuestos para la adquisición del nuevo concepto.

Una vez establecidos los objetivos se eligen los contenidos provenientes del programa de estudios en los cuales se pueden integrar los elementos básicos de la imagen en relación con las habilidades visuales específicas y las características de la edad del público meta. En esta segunda fase también se deben planificar las actividades de interacción que se emplearán con el fin de crear espacios para la vivencia y convivencia del concepto.

En la fase III se ejecutan los elementos básicos antes planificados en un espacio de interacción social en que se pueden dar relaciones concebidas y también espontáneas entre los niños y el niño con el docente. 


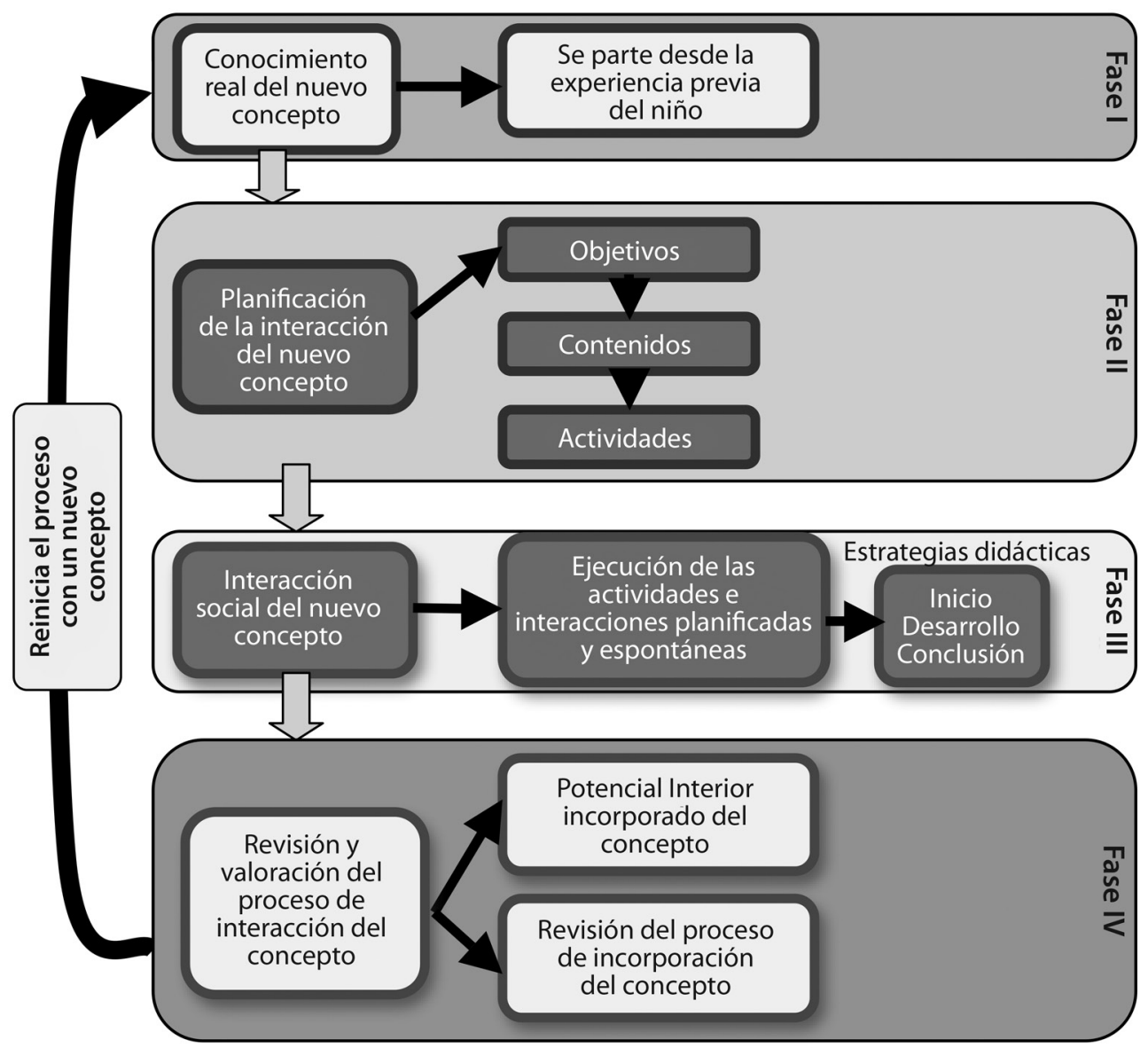

Figura 3. Esquema de la metodología para el Módulo Didáctico para la Alfabetización Visual en niños de 5 y 6 años de edad. Fuente. Elaboración propia.

Estas actividades contemplan un punto de inicio de la actividad que atraerá el interés del estudiante, el desarrollo de la misma y una etapa de cierre de la actividad (sin ser vista como una finalización del proceso).

En la fase IV del esquema se realiza una revisión del proceso de interacción experimentado, con el fin de evaluar los alcances del concepto socializado, así como la valoración del nivel potencial interior del niño como resultado del proceso de incorporación.

Una vez terminada la fase IV del esquema (figura 3), el proceso se vuelve a iniciar tomando en cuenta el mismo concepto cultural con un nuevo nivel de dificultad o se incorpora un nuevo concepto por socializar partiendo de una nueva secuencia y contenidos propuestos en el diseño curricular, respetando siempre el ritmo de los estudiantes. Se actuará bajo el mismo esquema en el caso que se requiera reforzar el concepto estudiado.

Debido al contexto en que se realizó la validación y comprobación de la metodología utilizada para el módulo, se incorporan los elementos didácticos de la metodología empleada en el programa de estudios del nivel preescolar costarricense; sin embargo, se formula bajo la intención de que se pueda extrapolar esta metodología específica a otros contextos educativos nacionales o internacionales, en los que se requiera involucrar la alfabetización visual, partiendo de la posibilidad de generalizar 
la fundamentación teórica aplicada a los niños y niñas en edad preescolar y a la contextualización social general antes mencionada.

\section{SÍNTESIS Y REFLEXIONES FINALES}

En estos tiempos en que las comunicaciones son masivas, el uso de la imagen se reviste de gran importancia, lo que impulsa a que la educación intervenga como formador de opiniones críticas ante la información recibida, sea capaz de discriminar los mensajes encriptados y de escoger de manera orientada lo que realmente necesita o requiere, así como las ideologías o tendencias sociales a las que puede acceder.

Debido a este contexto social de codificación de la información cultural en forma de imágenes, la alfabetización visual debe incorporarse a los procesos educativos formales desde los primeros años de exposición académica, es decir, desde el nivel de preescolar.

Para que la educación formal pueda intervenir en la decodificación e interpretación de la información implícita de la imagen, se requiere de la formulación de una metodología que dirija los esfuerzos de manera organizada y con fines específicos para cada grupo de edad. En el caso de la educación preescolar costarricense, el programa de estudios de este nivel no posee componentes específicos explícitos enfocados a este tipo de alfabetización de la manera que se explicó en apartados anteriores, como tampoco presenta, dentro de las unidades y contenidos, los elementos específicos de la imagen como parte de la estimulación general transversal del programa.

En síntesis, la presente propuesta metodológica es un elemento que apoya el proceso de alfabetización visual dentro del aula preescolar para, de esta manera, ir formando a los futuros adultos en la decodificación e interpretación de la información cultural y de valores provenientes de las imágenes que los rodean, así estimular las habilidades necesarias para que pueda tomar una decisión más libre sobre lo que desea o no incorporar a su acervo.

También se recomienda extender la investigación y ampliar la cobertura de esta metodología para que contribuya a la formación sistematizada de otros grupos de edad.

\section{REFERENCIAS}

Aparicio, R. y García, A. (1998). Lectura de Imágenes. Madrid: Ediciones de la Torre.

Aramburu, M. (2004). Jerome Seymour Bruner: De la percepción al lenguaje. Revista lberoamericana de Educación, 33 (7), agosto. OEl. Recuperado de http://www.rieoei.org/deloslectores/749Aramburu258.PDF

Barragán, R. y Gómez, W. (2012). El lenguaje de la imagen y el desarrollo de la actitud crítica en el aula: propuesta didáctica para la lectura de signos visuales. Revista Íkala de lenguaje y cultura, 17(1), enero-abril, pp. 79-92, Universidad de Antioquia, Medellín, Colombia. Recuperado de http://www.redalyc.org/articulo.oa?id=255024135006

Bruner, J. y Olson, D. (1973). Aprendizaje por experiencia directa y por experiencia mediatizada. Revista Perspectivas. UNESCO. Recuperado de http://www.riic.unam.mx/01/02_Biblio/doc/ AprendizajePorExperienciaDirecta_Bruner.pdf

Bruner, J. (1996) Realidad mental y mundos posibles. Barcelona: Gedisa.

Calle, M. (2008). La enseñanza de la lectura de imágenes. Revista digital Enfoques Educativos, 23, octubre, pp. 18-27. Recuperado de http://www.enfoqueseducativos.es/enfoques/enfoques_23.pdf 
Ferradini, S. y Tedesco, R. (1997) Lectura de la imagen. Revista Comunicar, (8), marzo, pp. 157-160. España. Recuperado de http://www.iar.unicamp.br/lab/luz/ld/Linguagem\%20Visual/lectura_de_la_imagen.pdf

Ferrer, M. y Guanipa, M. (2007). La alfabetización visual: forma de representación de ideas y complemento del lenguaje. Revista arbitrada de la Facultad de Arte de la Universidad del Zulia, (2), enero a junio. Consultado en http://revistas.luz.edu.ve/index.php/situarte/article/view/2500

Ferreras, J. y Vergilio, M. (2008). A vueltas con la alfabetización visual: lenguaje y significado en las películas de Wes Anderson. Revista Científica de Información y Comunicación, (5), 248-287. Recuperado de http://institucional.us.es/revistas/comunicacion/5/08ferreras.pdf

Hernández, J. I. (1993). Un modelo de microdiseño curricular: propuesta constructivista para la educación infantil (0 a 6 años). Revista de Educación, (301), 271-295. Recuperado de http://www.mecd.gob. es/revista-de-educacion/numeros-revista-educacion/numeros-anteriores/1993/re301/re301_13. html

Hernández, S. (2007). El constructivismo social como apoyo en el aprendizaje en línea. Revista Apertura, 7(7), noviembre, pp. 46-62. Recuperado de http://www.redalyc.org/articulo.oa?id=68800705

Ibarra, A y De la Llata, D. (, 2010). Niños nativos digitales en la sociedad del conocimiento: Acercamientos conceptuales a sus competencias. Revista Razón y palabra, (72), mayo a julio. Recuperado de http:// www.razonypalabra.org.mx/N/N72/Varia_72/14_Ibarra_72.pdf

León, S. (2006). Narrativas orales y lectura de imágenes en niños pre-escolares. Revista Pensamiento Psicológico, 2(7), pp. 113-131. Consultado en http://portales.puj.edu.co/psicorevista/components/ com_joomlib/ebooks/R7_Narrativas_orales.pdf

Llorente, E. (2000). Imágenes en la enseñanza. Revista Psicodidáctica, (9), 119-135. Universidad del País Vasco Vitoria-Gazteis, España. Recuperado de http://www.ehu.es/ojs/index.php/psicodidactica/ article/view/123/119

Moll, L. (1993) Vygotsky y la educación. Buenos Aires: Aique.

Regalado, M. (2008). Importancia de la alfabetización visual. Revista Eutopía, (7), julio a setiembre, pp. 28-33. Consultado en http://www.cch.unam.mx/comunicacion/sites/www.cch.unam.mx.comunicacion/files/subidas/eutopia_07_0.pdf

Rodríguez, S. (2008). Connotación y Persuasión de la Imagen publicitaria. Gazeta de Antropología, 24(2), diciembre, artículo 55. Recuperado de http://hdl.handle.net/10481/6958

Teubal, E. (2010). La contribución de los textos gráficos no verbales para el desarrollo de la alfabetización a temprana edad. IRICE Nueva Época, 21, pp.27-36. http://lenguajesytextos-educprimaria.bligoo. com.ar/media/users/22/1124525/files/303147/TEUBAL_TRADUCCION_La_contribuci_n_textos_ gr_ficos_no_verbales.pdf

Villa, N. (2008). Fundamentos, estructura e impacto de una propuesta de alfabetización visual apoyada en recursos hipermediales. Revista Educación y Pedagogía, 20(51), mayo a agosto. Recuperado de http://aprendeenlinea.udea.edu.co/revistas/index.php/revistaeyp/article/view/9906/9102

Vygotsky, L. (1979) El desarrollo de los procesos psicológicos superiores. Barcelona: Crítica. 